\title{
Low-cost Technological Strategies for Smallholders Sustainability: A Review
}

\author{
Eduardo Cornejo-Velazquez ${ }^{*}$, Otilio-Arturo Acevedo-Sandoval ${ }^{2}$,Hugo Romero-Trejo ${ }^{2}$, Alfredo Toriz-Palacios ${ }^{1}$
}

Abstract: Facing the challenges of the 21st century, into the agricultural sector have been designing strategies focused on the management of ecosystem resources, risk management associated with crops and the promotion of sustainable growth of agricultural communities. These strategies have been configured considering functional and competitive levels for open agricultural production systems, and usually based on low-cost technologies such that Wireless Sensor Networks (WSN), Internet of Things (IoT), Unmanned Aerial Vehicles (UAV), Cloud Computing, and Computational Algorithms. This approach allows the configuration, planning, and implementation of technological strategies for the agricultural sector, impacting in a positive way, generating higher production levels and intensive production cycles to strengthen the smallholder farmers.

Keywords: technological strategic; low-cost technologies; smallholders; remote sensing.

Submitted: May $3^{\text {rd }}, 2019 /$ Approved: May $12^{\text {th }}, 2020$

\section{Introduction}

Consequences of global warming are evident, floods, droughts and storm are more frequent and intense, these provoke adverse impacts on the agricultural sector, being a threat for food security (Bayala, Zougmoré, Dayamba, \& Olivier, 2017; FAOd, 2017; Singh \& Singh, 2017; Valentini, 2017; Zilberman, Goetz, \& Garrido, 2018). FAO (2015) estimates that by the year 2050 the world population will reach 9 billion people, consequently the food demand will require an increase in its production of at least $60 \%$, compare to 2007 levels (Chiriboga, 2015; FAOb, 2015). European Union (EU, 2016) projects that increase in food production will come in $77 \%$ of developing countries and $23 \%$ in developed countries. In developing countries, $80 \%$ of this required increase will have to come from higher yields and greater intensity of crops, and only 20\% from arable land (FAOd, 2017).
The human being is facing up the degradation of natural resources and decrement of available water, those factors together with the limitations of the area of arable land are provoking a substantial and dangerous reduction in crop yields (FAOb, 2015). In this scenario, the application of Information and Communication Technologies (ICT) in agricultural systems, Figure 1, offers the possibility of transforming currently field practices (Zhang, Wang, \& Duan, 2016) and modifying their configuration by making them collaborative, distributed, and flexible (Janssen et al., 2017), positively impacting in the level crops yield.

Figure 1. ICT in agricultural environment.

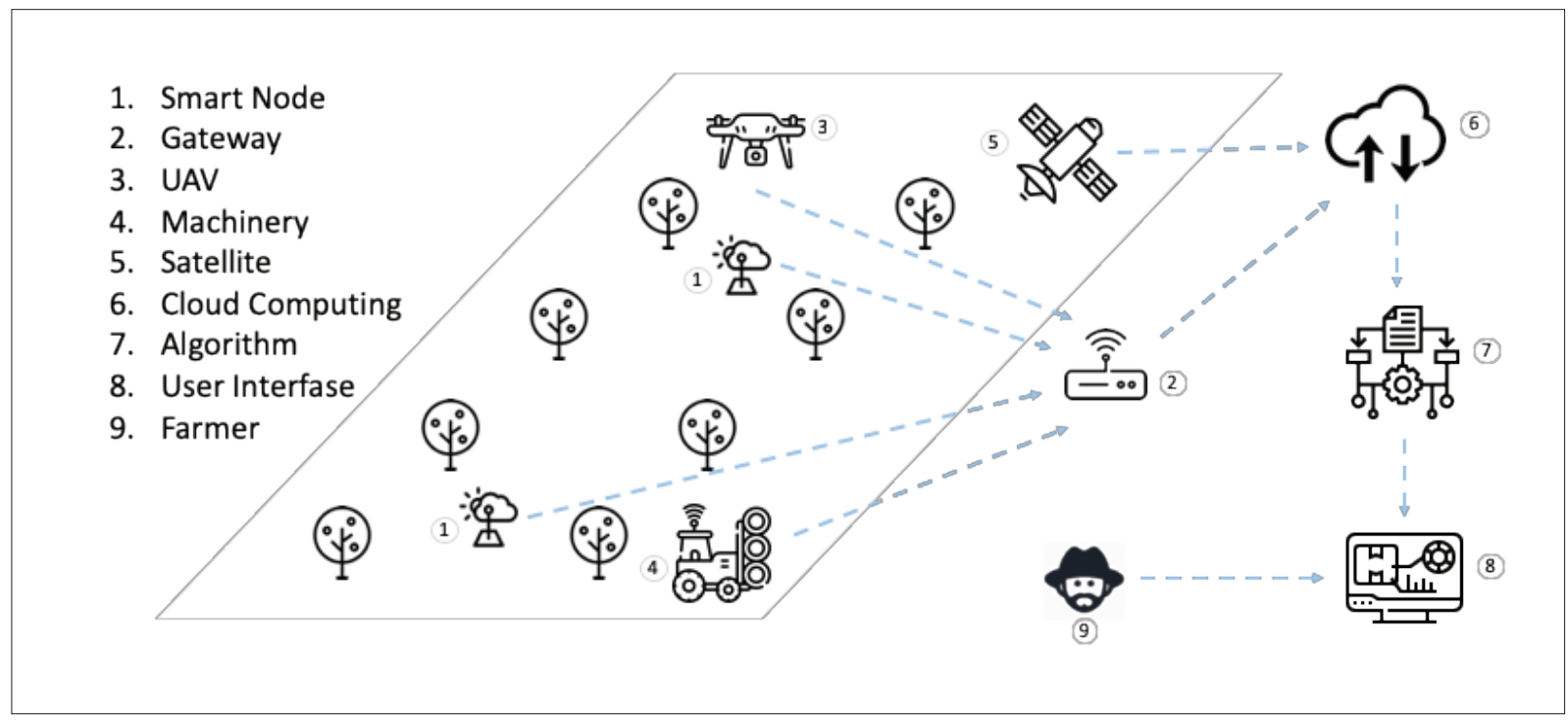

(1) Department of Strategic Planning and Technology Direction, Autonomous Popular University of the State of Puebla, Puebla, Mexico.

(2) Institute of Basic Sciences and Engineering, Autonomous University of the State of Hidalgo, Pachuca, Hidalgo, Mexico

* Corresponding author: eduardo.cornejo@upaep.edu.mx 
The rapid development of digital technologies, and their potential to transform agricultural production systems is increasing, above all, by providing development opportunities that support greater digital inclusion of smallholder producers and opening of new opportunities in this sector. Modern agricultural production systems are incorporating strategies that integrate technology, data and knowledge (Antle, Jones, \& Rosenzweig, 2017; Jones et al., 2017) in order to support planning processes and analysis of strategic decisions guided by data collection and analysis (Janssen et al., 2017). These strategies allow to design of forecasting programs as well as safe crop plans to manage risks and improve the productivity (McCarthy, Lipper, \& Zilberman, 2018; Pallottino et al., 2018; Zilberman et al., 2018).

However, a critical challenge of the agricultural sector is the high cost for the adoption of new technologies, especially for small and medium-sized farmers in developing countries. In this paper we identified technological strategies focused on strengthening the competitive advantages of smallholder agricultural producers, all them in order to face up the food challenges of the 21st century, with emphasis on the use of low-cost digital technologies at the level to farming plots. In this context, the following research questions are formalized: what is the purpose of the technological strategies? and, what are the low-cost digital technologies available to smallholders?

\section{Methodological considerations}

For the identification of the scientific literature, the following databases were searched: Science Direct, Elsevier, Springer and Google Scholar with the terms "smallholder" AND "agriculture" AND "technologies" OR "innovation", and considering works published in the last 3 years. Then, preliminary results were filtered using concepts "sensor networks" OR "Internet of Things" OR "cloud computing" OR "Unmanned Aerial Vehicle". They were grouped taking into account the proposed aims and were related to the European Union's agenda (EU, 2016) regarding the priority areas of research and innovation in the agriculture field.

Finally, the digital agriculture model for monitoring the crop, forest and water ecosystems of Popovic et al. (2017) was considered to identify the stage of data processing, the digital technologies used and the functional purpose of the analyzed works (Popović et al., 2017). Particularly this model has an aim to produce a research and development platform from a point of view of sustainable agriculture, and its application allows to design techniques to controlling and reducing the pollution, control of quality of land, standardization of food production, and improvement of public health.

\section{Results}

Results of the literature review identified three types of strategies that employ low-cost digital technologies: resource management, risk management and strengthening sustained growth, which are described in the following section.

\section{Technological strategies of natural resource management}

Understanding dynamic interaction between agricultural ecosystems, use of resources and climate allows to define technological strategies for natural resource management (water, soil and biodiversity) to obtain a balance between productivity and sustainability.

Digital technologies allow automatic data collection of the environment, soil, fertilization, irrigation, and crop development (Balafoutis et al., 2017). With data, it is possible to use the natural resources of the agroecosystem intelligently, improve the adaptation to the variability of climatic conditions and increase the agricultural potential. Remote monitoring technologies support the adaptation of agricultural practices (i.e. fertilization, irrigation, fumigation) in order to optimize the production costs and improve the quality of products (Dorigo et al., 2007; Jin et al., 2018).

Wireless Sensor Networks (WSN) in the agricultural field allow to capture data of physical, chemical, and biological variables that enable the monitoring and control of the production process and guarantee the quality of agricultural products (Føre et al., 2017; Gongal et al., 2016; Pivoto et al., 2018; Rodríguez, Gualotuña, \& Grilo, 2017). Incorporating the open technologies of the Internet of Things (IoT) to WSN, it allows to collect automatically and in real-time the environmental data, development and health crops, soil moisture and nutrients, application of irrigation (Alahi, Pereira-Ishak, \& Burkitt, 2018; Chand, Chand, Sidhendra, \& Hussain, 2018; Mekala \& Viswanathan, 2018).

Extending about (Alahi et al., 2018), in this work the authors report the design and validation of a sensor to measure the nitrate concentration, it has been deployed inside of a smart sensing node which recollect data and transmit them to a cloud server in real-time. The use of this kind of technology and architecture avoid the outline laboratory tests offering new possibilities for spatial and temporal analysis.

In addition, to extend the functionalities of technological platforms, it is possible to integrate cameras and meteorological stations, sensors based on open hardware and low energy consumption (Ferrández-Pastor, García-Chamizo, Nieto-Hidalgo, \& Mora-Martínez, 2018; Jayaraman, Yavari, Georgakopoulos, Morshed, \& Zaslavsky, 2016; Popović et al., 2017) . In (Hamouda \& Msallam, 2018) authors proposed a system to measure the agricultural parameters, predict subsequent values, and select the sensing sensor nodes and sampling interval pro-actively with aims to filter measurement noise, increase sensing accuracy, improve energy efficiency, and enhance WSN lifetime.

Technologies of WSN, IoT and analysis software allow the implementation of automatic irrigation systems to minimize human intervention. The systems monitoring humidity, temperature and macronutrients of the soil (Raut, Varma, Mulla, \& Pawar, 2018) and offer solutions focused on agricultural producers (Ferrández-Pastor et al., 2018). Authors in (Karim, Karim, \& Frihida, 2017) described an application prototype for precision farming combining a WSN with 
an IoT cloud via web services, and it allows real-time supervision of microclimatic conditions of the crop in order to know the water needs and optimize water use.

A comparative analysis for technical characteristics of hardware and software of the low-cost platforms reported in the analyzed literature allow we describe the principal components. Microcontrollers are mainly based on the open hardware of Arduino and Raspberry Pi; to wireless communication they apply ZigBee, WiFi and GPRS technologies; sensors installed are DHT11 and DHT22 for temperature and humidity, FC-28 and SEN9235SP for soil moisture and LDR for luminosity; for Data storage choice were Ubidots, MongoDB and private repositories; and, data analysis are based on computational algorithms that employ linear regression techniques, Artificial Neural Networks (ANN), Support Vector Machine (SVM), Bayesian classifiers and predictive models of Machine Learning (ML) (FerrándezPastor et al., 2018; Karim et al., 2017; Montoya, Colorado, Muñoz, \& Golondrino, 2017; Popović et al., 2017; Rodríguez et al., 2017).

Another used technology is the Unmanned Aerial Vehicles (UAV), within the agricultural ecosystems this technology allows to design technological strategies for data assimilation and focused to monitoring of agricultural production systems (Domingues Franceschini, Bartholomeus, van Apeldoorn, Suomalainen, \& Kooistra, 2017). Low-cost aerial platforms are equipped with cameras to collect images of crops, which are processed by computational algorithms to compute vegetation indices, which are used to support the discrimination of plants species (Handique et al., 2017; Oldeland, GroßeStoltenberg, Naftal, \& Strohbach, 2017), monitoring based on phenotypes (Burkart, Hecht, Kraska, \& Rascher, 2018) and determination of water status (Martínez, Egea, Agüera, \& Pérez-Ruiz, 2017). According to this approach, in (Romero, Luo, Su, \& Fuentes, 2018) authors employed multispectral imagery from a UAV platform to water status estimation and machine learning algorithms for optimal irrigation scheduling management and to identify spatial variability within the crop field.

It is so that now and for the future, the digital technologies of remote monitoring applied to agricultural field have a major relevance, because they are supporting to smallholders in order to take and apply strategic decisions related to planning and evaluation of field practices, improving the efficiency of production process (involving a higher food production, and reducing costs).

\section{Technological crop risk management strategies}

The target for technological crop risk management strategies is to design efficient tools for prevention, monitoring, control, and management of weeds, pests, and diseases. Smallholders cultivation fields are heterogeneous, so it is necessary to use different tools to manage the distinct type of risk.

According to the scientific literature review, UAV technology empowers implementation of crop monitoring strategies to determine the health status (Khan, Rahimi-Eichi, Haefele, Garnett, \& Miklavcic, 2018), nitrogen, and other nutrients levels (L. A. Hunt \& Boote, 1998; Krienke et al., 2017). It can provide data that enable the targeted application of agricultural task and products on areas previously identified and limited by means of computer algorithms, and it is through this technology application that the precision agriculture make sense. Images collected by UAV allows the construction of crop geolocation maps where is possible determine areas with weeds (Barrero \& Perdomo, 2018), allowing to program the herbicides application in the critical zones (Yang, Yang, \& Mo, 2018).

Additionally, crop maps enable to monitoring the results of the fertilizers and herbicides application to evaluate their efficiency and make adjustments in a dynamic and flexible way (Castaldi, Pelosi, Pascucci, \& Casa, 2017). In case of (Schut, Traore, Blaes, \& de By, 2018) the authors worked with smallholder farms to demonstrate how the images collected by an UAV can be used to assess the spatial variability in yields and response to different fertilizer treatment.

For the pests management, UAV flies over crop to collect insects (Kim, Park, \& Lee, 2018) in order to classificate species or identify pathogens (West, Canning, Perryman, \& King, 2017), which is useful to configure plans with specific actions. Recently, UAV's have been tested as a tool to scare away birds invasion that damage the harvest (Segun, Sunday, Ogunti, \& Akingbade, 2018). Table 1 show a comparative analysis of technical characteristics of the aerial platforms analyzed in the literature. The models of flexible wing considered are designed and manufactured by companies as DJI, 3D Robotics and OktoKopter, in configurations of quadcopters, hexacopters, and octocopters, as well as models of fixed wing of the companies SenseFly and Zeta. 
Table 1. Low-cost aerial platforms for smallholder producers. Source: Authors (2019).

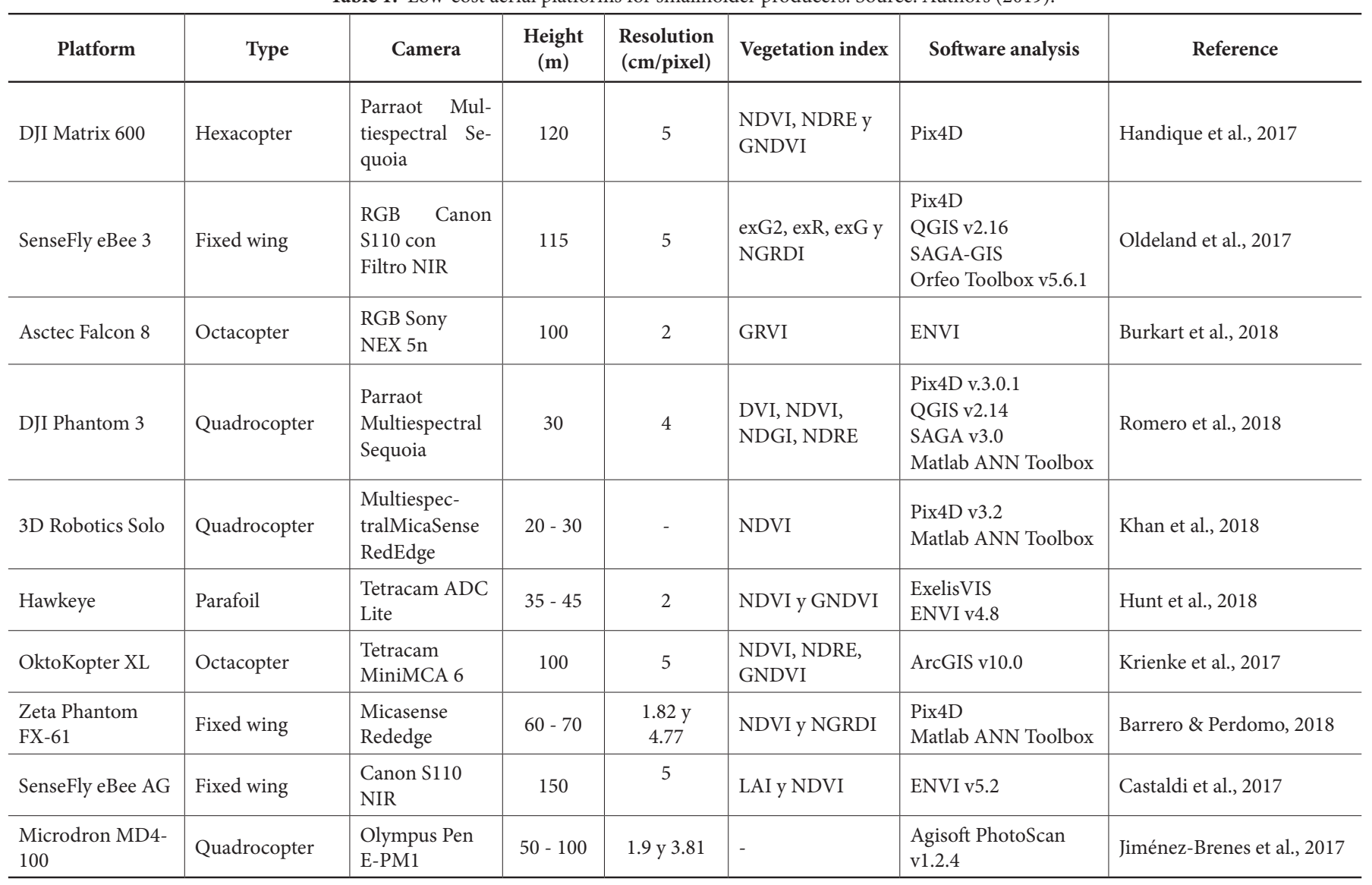

The aircraft is usually equipped with multispectral cameras like Parrot Sequoia or Mica Sense RedEdge, or RGB cameras as Canon S110, Sony NEX 5n, and Olympus Pen E-PM1. The aerial image collections are made in the range of 5 and 120 meters of height, reaching resolutions between 2 and 5 centimeters per pixel. The Normalized Difference Vegetation Index (NDVI), Normalized Difference Red Edge Index (NDRE), Green Normalized Difference Vegetation Index (GNDVI), Green-Red Vegetation Index (GRVI), are the main Vegetation Indices (VI) computed from the analysis of the images obtained by computing platforms as Pix4D, QGIS, ArcGIS, and Matlab ANN Toolbox. Understanding

\section{Technological strategies for sustainable growth}

Technological strategies focused on promoting sustainable growth in rural areas promote the strengthening of the skills, human and social capital of farmers to expand sustainability and boost agricultural economies. Agricultural software ecosystems uses technological tools in the massive generation of a variety of data that are collected and analyzed to be used in the planning and analysis of the strategic decisions (Kruize et al., 2016). In (Musat et al., 2018) the authors stated that software tools support the operation of collaborative systems permitting to the smallholders producers to efficiently manage their crops, and they also facilitate the interaction with other agricultural agents and actors in the sector. The software platforms carry out the data collection and given the opportunity to send notifications to other producers in case of generalized problems, or if they are issues of common interest for the agricultural community.

A particular case is (Jiménez-Brenes et al., 2017) where the application of UAV was described to evaluate the pruning techniques in olive trees and analyze their impact on harvest, nutrition, pest control, and diseases. These strategies allow the strengthening knowledge of the producers and reinforce the sustainability of the crops through evaluation and validation of the field practices.

Technological strategies for sustainable growth look to boost agricultural economies through the exchange of data and knowledge between different actors in the sector, the strengthening of rural communities and the evaluation of field practices. In this sense, the technologies should provide innovative solutions with high social and economically viable impact.

Technological strategies for sustainable growth look to boost agricultural economies through the exchange of data and knowledge between different actors in the sector, the strengthening of rural communities and the evaluation of field practices. In this sense, the technologies should provide innovative solutions with high social and economically viable impact. 


\section{Discussion}

Technological strategies strengthen the agricultural production process through the use of digital technologies that systematize and automate work in agricultural systems. Traditional agricultural management is transformed into a more flexible and dynamic one, based on real-time data collection of variables of interest for crop planning and supervision. The agricultural monitoring systems enable their configuration at different spatial and temporal scales in relation to the resources of the ecosystems, the extension of the plots, the types of crops and the objectives that are pursued.

At the level of smallholders producers, these strategies require to be configured and implemented using low-cost digital technologies. In infrastructure level, to achieve the interoperability of the data and facilitate its use; at the level of sensors and actuators, to deploy automated systems; and, at the application level, to be implemented in the different parts of the agricultural production process in order to build competitive advantages.

Different monitoring systems architectures have been proposed, some focused on natural resource management (Ferrández-Pastor et al., 2018; Hamouda \& Msallam, 2018; Karim et al., 2017; Popović et al., 2017; Raut et al., 2018) whereas other for support to strengthening sustainable growth (Kruize et al., 2016; Musat et al., 2018). These general architectures must be adjusted to the heterogeneity of the fields and the availability of energy sources and data communication technologies.
The strategies of resource management have been defined for specific crops: apples (Gongal et al., 2016), rice (Chand et al., 2018; Mekala \& Viswanathan, 2018), roses (Rodríguez et al., 2017), potatoes (Domingues Franceschini et al., 2017), barley (Burkart et al., 2018), sugar beet (Martínez et al., 2017), and vineyards (Romero et al., 2018). Therefore, they must be adapted to the requirements of new crops and field conditions for open system production. In addition, these strategies require the commitment of the smallholders related with the rational and efficient use of the available natural resources in the agricultural ecosystem for their success.

The risk management strategies proposed by (Khan et al., 2018; West et al., 2017) in wheat, (E. R. Hunt et al., 2018) in potatoes, (Barrero \& Perdomo, 2018; Kim et al., 2018; Segun et al., 2018) in rice, Icite\{Schut2018\} in cotton, corn, sorghum, millet and peanut, (Castaldi et al., 2017; Krienke et al., 2017) in corn, Icite\{Oldeland2017\} in trees species of the savannah, and (Jiménez-Brenes et al., 2017) on olive trees, all them base their results on the knowledge, analysis, and interpretation of the vegetation index. Then, these strategies require the participation of expert personnel, who interpret the data and provide support to the smallholders, this fact complicates its operation.

The different technologies implemented in the studied cases according to their functional purpose are grouped into sensors, communication networks, data integration, enhanced intelligence and increased performance in the digital agriculture model as presented in Figure 2.

Figure 2. Low-cost technologies deployed in the literature studied.

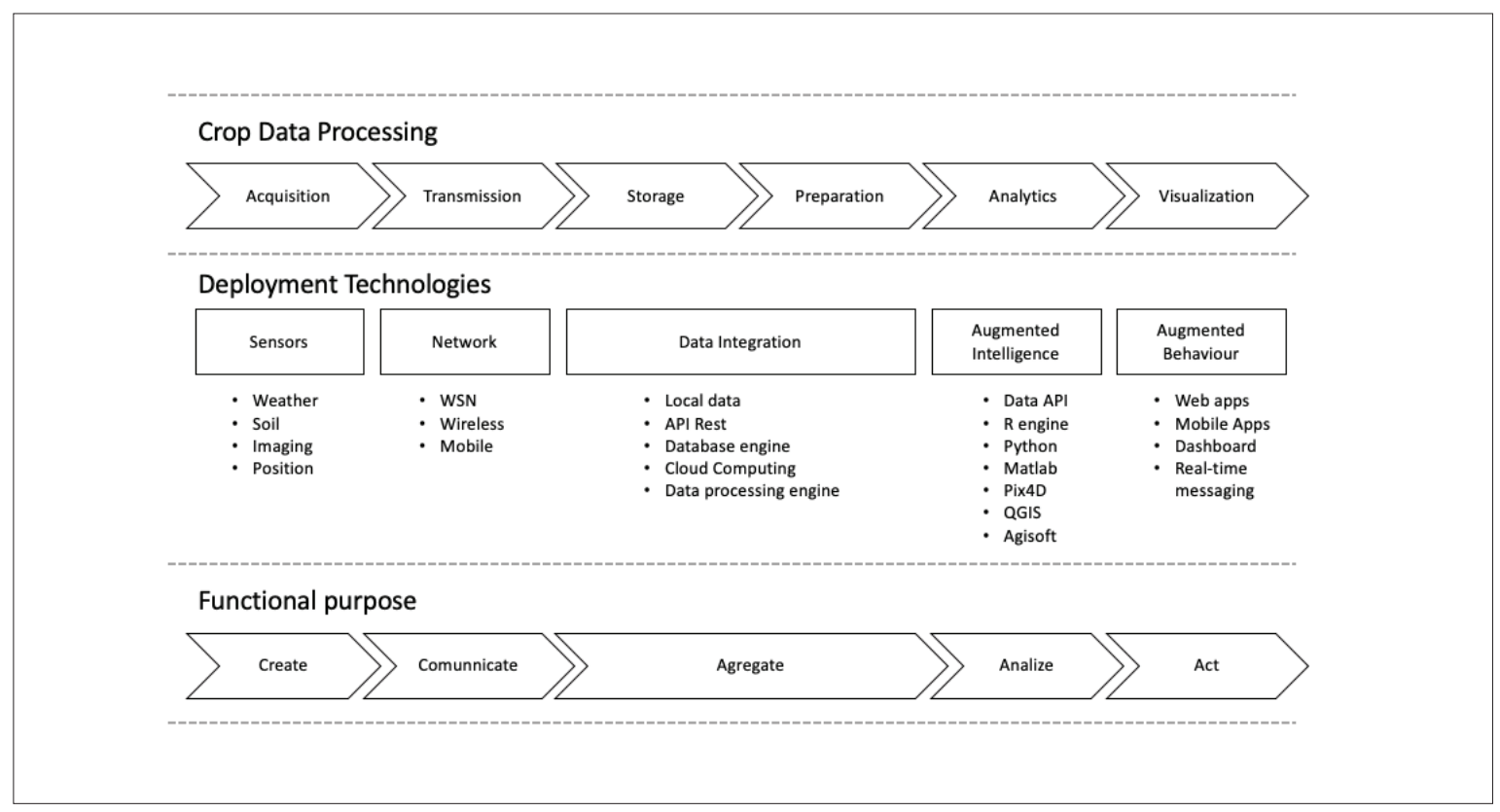

A key point for the success of the technological strategies is the implementation of the increased behavior, therefore it is necessary to employ technologies of visualization in order to present in a clear and easy way the data interpretation and then the results. All them will provoke the strengthen of understanding of the smallholders about how the crop is evolving. This will contribute to the sustainable growth of agricultural economies through strengthen knowledge, communication, and collaboration. 
It is important the involve to the smallholders producers in the process to design and planning of the technological strategies to delimit and define the requirements to be covered. In addition, is relevant that the strategies incorporate aspects related to the training, transfer, and adoption of digital technologies.

The purpose of this section is to evaluate and interpret the results, especially with respect to the original research question. Start off with a brief, non-technical summary of the results. In other words, tell the reader about the main findings without using statistical terminology. Then go on to discuss the implications of the results. It is also important to discuss how the results relate to the literature you cited in the introduction. In other words, emphasize any theoretical consequences of the results.

You might (or might not) also mention any limitations of the study and any suggestions for future research in this section. Finally, you need an ending paragraph in which you make a final summary statement of the conclusions you have drawn. You are also encouraged, when appropriate, to comment on the importance and relevance of your findings. How are your findings related to the big picture? Thus, this section should contain an absolute minimum of three paragraphs: the non-technical summary, discussion of the results and their implications, and the concluding paragraph.

\section{Conclusions}

Technological strategies implemented in the agricultural sector are mainly focused on the management of natural resources, the management of crop risks and the strengthening of sustainable growth of the community through the application of digital technologies. At the functional level, the technological strategies are mainly devoted to the automation of data collection tasks, the data becomes from many sources (sensor nodes) and it is related to different components of the agricultural production system. At the competitive level, it helps to build competitive advantages by reducing production costs, improving yields, ensuring quality, or increasing crop intensity.

Low-cost digital technologies possibility the construction of affordable solutions for smallholders producers. Strengthening the agricultural production systems and providing information, which permit planning and applying field practices at the preventive and corrective levels in a more efficient way.

Analyzed scientific literature describe positive impacts on the competitive advantages of smallholder producers; however, it is necessary to involve a greater number of them, diversify the application in more types of crops, and expand the areas monitored to maximize the benefits in the agricultural sector.

Finally, the scientific community still working to solve technical problems related to energy restriction, connectivity, limited computing capacity, small available memory, and data security.

\section{References}

Alahi, M. E. E., Pereira-Ishak, N., \& Burkitt, L. (2018). An Internet-ofThings enabled Smart Sensing System for Nitrate Monitoring. IEEE Internet of Things Journal. https://doi.org/10.1109/JIOT.2018.2809669

Antle, J. M., Jones, J. W., \& Rosenzweig, C. E. (2017). Next generation agricultural system data, models and knowledge products: Introduction. Agricultural Systems, 155, 186-190. https://doi.org/10.1016/J. AGSY.2016.09.003

Balafoutis, A. T., Beck, B., Fountas, S., Tsiropoulos, Z., Vangeyte, J., van der Wal, T., ... Pedersen, S. M. (2017). Smart Farming Technologies - Description, Taxonomy and Economic Impact. In S. M. Pedersen \& K. M. Lind (Eds.), Precision Agriculture: Technology and Economic Perspectives (pp. 21-77). Springer, Cham. https://doi.org/10.1007/978-3-319-68715-5_2

Barrero, O., \& Perdomo, S. A. (2018). RGB and multispectral UAV image fusion for Gramineae weed detection in rice fields. Precision Agriculture, 1-14. https://doi.org/10.1007/s11119-017-9558-x

Bayala, J., Zougmoré, R., Dayamba, S. D., \& Olivier, A. (2017). Editorial for the Thematic Series in Agriculture \&Food Security: ClimateSmart Agriculture Technologies in West Africa: learning from the ground AR4D experiences. Agriculture \& Food Security, 6(1), 40. https://doi.org/10.1186/s40066-017-0117-5

Burkart, A., Hecht, V. L., Kraska, T., \& Rascher, U. (2018). Phenological analysis of unmanned aerial vehicle based time series of barley imagery with high temporal resolution. Precision Agriculture, 19(1), 134-146. https://doi.org/10.1007/s11119-017-9504-y

Castaldi, F., Pelosi, F., Pascucci, S., \& Casa, R. (2017). Assessing the potential of images from unmanned aerial vehicles (UAV) to support herbicide patch spraying in maize. Precision Agriculture, 18(1), 76-94. https://doi.org/10.1007/s11119-016-9468-3

Chand, K. G., Chand, K. G., Sidhendra, M., \& Hussain, D. M. A. (2018). Soil nutrient measurement in paddy farming using IoT. International Journal of Engineering \& Technology, 7(2.7), 356-358. https://doi.org/10.14419/ijet.v7i2.7.10718

Chiriboga, M. (2015). Pequeñas economías: reflexiones sobre la agricultura familiar campesina. (FAO, Ed.). Quito, Ecuador: FAO.

Domingues Franceschini, M., Bartholomeus, H., van Apeldoorn, D., Suomalainen, J., \& Kooistra, L. (2017). Intercomparison of Unmanned Aerial Vehicle and Ground-Based Narrow Band Spectrometers Applied to Crop Trait Monitoring in Organic Potato Production. Sensors, 17(6), 1428. https://doi.org/10.3390/s17061428

Dorigo, W. A., Zurita-Milla, R., de Wit, A. J. W., Brazile, J., Singh, R., \& Schaepman, M. E. (2007). A review on reflective remote sensing and data assimilation techniques for enhanced agroecosystem modeling. International Journal of Applied Earth Observation and Geoinformation, 9(2), 165-193. https://doi.org/10.1016/J.JAG.2006.05.003 
EU. (2016). A strategic approach to EU agricultural. Brussels, Belgium. Retrieved from https://ec.europa.eu/programmes/horizon2020/sites/ horizon2020/files/agri_strategypaper_web_1.pdf

FAOb. (2015). Climate-Smart Agriculture: A call for action. (FAO, Ed.), Synthesis of the Asia-Pacific Regional Workshop Bangkok, Thailand, 18 to 20 June 2015. Retrieved from http://www.fao.org/3/a-i4904e.pdf

FAOd. (2017). El estado de la seguridad alimentaria y la nutrición en el mundo.

Ferrández-Pastor, F., García-Chamizo, J., Nieto-Hidalgo, M., \& Mora-Martínez, J. (2018). Precision Agriculture Design Method Using a Distributed Computing Architecture on Internet of Things Context. Sensors, 18(6), 1731. https://doi.org/10.3390/s18061731

Føre, M., Frank, K., Norton, T., Svendsen, E., Alfredsen, J. A., Dempster, T., ... Berckmans, D. (2017). Precision fish farming: A new framework to improve production in aquaculture. Biosystems Engineering. https://doi.org/10.1016/J.BIOSYSTEMSENG.2017.10.014

Gongal, A., Silwal, A., Amatya, S., Karkee, M., Zhang, Q., \& Lewis, K. (2016). Apple crop-load estimation with over-the-row machine vision system. Computers and Electronics in Agriculture, 120, 26-35. https://doi.org/10.1016/J.COMPAG.2015.10.022

Hamouda, Y. E. M., \& Msallam, M. M. (2018). Smart heterogeneous precision agriculture using wireless sensor network based on extended Kalman filter. Neural Computing and Applications. https://doi. org/10.1007/s00521-018-3386-4(

Handique, B. K., Khan, A. Q., Goswami, C., Prashnani, M., Gupta, C., \& Raju, P. L. N. (2017). Crop Discrimination Using Multispectral Sensor Onboard Unmanned Aerial Vehicle. Proceedings of the $\mathrm{Na}$ tional Academy of Sciences, India Section A: Physical Sciences, 87(4), 713-719. https://doi.org/10.1007/s40010-017-0443-9

Hunt, E. R., Horneck, D. A., Spinelli, C. B., Turner, R. W., Bruce, A. E., Gadler, D. J., ... Hamm, P. B. (2018). Monitoring nitrogen status of potatoes using small unmanned aerial vehicles. Precision Agriculture, 19(2), 314-333. https://doi.org/10.1007/s11119-017-9518-5

Hunt, L. A., \& Boote, K. J. (1998). Data for model operation, calibration, and evaluation (pp. 9-39). Springer, Dordrecht. https://doi. org/10.1007/978-94-017-3624-4_2

Janssen, S. J. C., Porter, C. H., Moore, A. D., Athanasiadis, I. N., Foster, I., Jones, J. W., \& Antle, J. M. (2017). Towards a new generation of agricultural system data, models and knowledge products: Information and communication technology. Agricultural Systems, 155, 200-212. https://doi.org/10.1016/J.AGSY.2016.09.017

Jayaraman, P., Yavari, A., Georgakopoulos, D., Morshed, A., \& Zaslavsky, A. (2016). Internet of Things Platform for Smart Farming: Experiences and Lessons Learnt. Sensors, 16(11), 1884. https://doi. org/10.3390/s16111884
Jiménez-Brenes, F. M., López-Granados, F., de Castro, A. I., TorresSánchez, J., Serrano, N., \& Peña, J. M. (2017). Quantifying pruning impacts on olive tree architecture and annual canopy growth by using UAV-based 3D modelling. Plant Methods, 13(1), 55. https://doi. org/10.1186/s13007-017-0205-3

Jin, X., Kumar, L., Li, Z., Feng, H., Xu, X., Yang, G., \& Wang, J. (2018). A review of data assimilation of remote sensing and crop models. European Journal of Agronomy, 92, 141-152. https://doi.org/10.1016/J. EJA.2017.11.002

Jones, J., Antle, J., Basso, B., Boote, K., Conant, R., Foster, I., ... Wheeler, T. (2017). Brief history of agricultural systems modeling. Agricultural Systems, 155, 240-254. https://doi.org/10.1016/J. AGSY.2016.05.014

Karim, F., Karim, F., \& Frihida, A. (2017). Monitoring system using web of things in precision agriculture. Procedia Computer Science, 110, 402-409. https://doi.org/10.1016/J. PROCS.2017.06.083

Khan, Z., Rahimi-Eichi, V., Haefele, S., Garnett, T., \& Miklavcic, S. J. (2018). Estimation of vegetation indices for highthroughput phenotyping of wheat using aerial imaging. Plant Methods, 14(1), 20. https://doi.org/10.1186/s13007-0180287-6

Kim, H. G., Park, J.-S., \& Lee, D.-H. (2018). Potential of Unmanned Aerial Sampling for Monitoring Insect Populations in Rice Fields. Florida Entomologist -, 101(2), 330-334. https://doi. org/10.1653/024.101.0229

Krienke, B., Ferguson, R. B., Schlemmer, M., Holland, K., Marx, D., \& Eskridge, K. (2017). Using an unmanned aerial vehicle to evaluate nitrogen variability and height effect with an active crop canopy sensor. Precision Agriculture, 18(6), 900-915. https://doi.org/10.1007/ s11119-017-9534-5

Kruize, J. W., Wolfert, J., Scholten, H., Verdouw, C. N., Kassahun, A., \& Beulens, A. J. M. (2016). A reference architecture for Farm Software Ecosystems. Computers and Electronics in Agriculture, 125, 12-28. https://doi.org/10.1016/j.compag.2016.04.011

Martínez, J., Egea, G., Agüera, J., \& Pérez-Ruiz, M. (2017). A costeffective canopy temperature measurement system for precision agriculture: a case study on sugar beet. Precision Agriculture, 18(1), 95-110. https://doi.org/10.1007/s11119-016-9470-9

McCarthy, N., Lipper, L., \& Zilberman, D. (2018). Economics of Climate Smart Agriculture: An Overview. In Climate Smart Agriculture Building Resilience to Climate Change (pp. 31-47).

Mekala, M. S., \& Viswanathan, P. (2018). CLAY-MIST: IoTCloud Enabled CMM index for Smart Agriculture Monitoring System. Measurement. https://doi.org/10.1016/J.MEASUREMENT.2018.10.072 
Montoya, E. A. Q., Colorado, S. F. J., Muñoz, W. Y. C., \& Golondrino, G. E. C. (2017). Propuesta de una Arquitectura para Agricultura de Precisión Soportada en IoT. RISTI - Revista Ibérica de Sistemas e Tecnologias de Informação, (24), 39-56. https://doi.org/10.17013/ risti.24.39-56

Musat, G.-A., Colezea, M., Pop, F., Negru, C., Mocanu, M., Esposito, C., \& Castiglione, A. (2018). Advanced services for efficient management of smart farms. Journal of Parallel and Distributed Computing, 116, 3-17. https://doi.org/10.1016/J.JPDC.2017.10.017

Oldeland, J., Große-Stoltenberg, A., Naftal, L., \& Strohbach, B. J. (2017). The Potential of UAV Derived Image Features for Discriminating Savannah Tree Species. In The Roles of Remote Sensing in Nature Conservation (pp. 183-201). Cham: Springer International Publishing. https://doi.org/10.1007/978-3-319-64332-8_10

Pallottino, F., Biocca, M., Nardi, P., Figorilli, S., Menesatti, P., \& Costa, C. (2018). Science mapping approach to analyze the research evolution on precision agriculture: world, EU and Italian situation. Precision Agriculture, 1-16. https://doi.org/10.1007/s11119-018-9569-2

Pivoto, D., Waquil, P. D., Talamini, E., Finocchio, C. P. S., Dalla Corte, V. F., \& de Vargas Mores, G. (2018). Scientific development of smart farming technologies and their application in Brazil. Information Processing in Agriculture. https://doi.org/10.1016/j.inpa.2017.12.002

Popović, T., Latinović, N., Pešić, A., Zečević, Ž., Krstajić, B., \& Djukanović, S. (2017). Architecting an IoT-enabled platform for precision agriculture and ecological monitoring: A case study. Computers and Electronics in Agriculture, 140, 255-265. https://doi.org/10.1016/J. COMPAG.2017.06.008

Raut, R., Varma, H., Mulla, C., \& Pawar, V. R. (2018). Soil Monitoring, Fertigation, and Irrigation System Using IoT for Agricultural Application. In Intelligent Communication and Computacional Technologies (pp. 67-73). Springer, Singapore. https://doi.org/10.1007/978-98110-5523-2_7

Rodríguez, S., Gualotuña, T., \& Grilo, C. (2017). A System for the Monitoring and Predicting of Data in Precision Agriculture in a Rose Greenhouse Based on Wireless Sensor Networks. Procedia Computer Science, 121, 306-313. https://doi.org/10.1016/j.procs.2017.11.042
Romero, M., Luo, Y., Su, B., \& Fuentes, S. (2018). Vineyard water status estimation using multispectral imagery from an UAV platform and machine learning algorithms for irrigation scheduling management. Computers and Electronics in Agriculture, 147, 109-117. https:// doi.org/10.1016/J.COMPAG.2018.02.013

Schut, A. G. T., Traore, P. C. S., Blaes, X., \& de By, R. A. (2018). Assessing yield and fertilizer response in heterogeneous smallholder fields with UAVs and satellites. Field Crops Research, 221, 98-107. https:// doi.org/10.1016/J.FCR.2018.02.018

Segun, A., Sunday, O. I., Ogunti, E. O., \& Akingbade, F. K. (2018). Solution to Bird Pest on Cultivated Grain Farm: A Vision Controlled Quadcopter System Approach. International Journal of Engineering \& Technology, 7(10). Retrieved from www.ijert.org

Singh, R., \& Singh, · G S. (2017). Traditional agriculture: a climatesmart approach for sustainable food production. Energy, Ecology and Environment, 2(5), 296-316. https://doi.org/10.1007/s40974-0170074-7

Valentini, R. (2017). the global agricultural System and climate change: challenges and opportunities for the russian federation * актуальнаЯ тEMa. FINANCE: THEORY AND PRACTICE, 21(6), 5671-2017. https://doi.org/10.26794/2587

West, J. S., Canning, G. G. M., Perryman, S. A., \& King, K. (2017). Novel Technologies for the detection of Fusarium head blight disease and airborne inoculum. Tropical Plant Pathology, 42(3), 203-209. https://doi.org/10.1007/s40858-017-0138-4

Yang, S., Yang, X., \& Mo, J. (2018). The application of unmanned aircraft systems to plant protection in China. Precision Agriculture, 19(2), 278-292. https://doi.org/10.1007/s11119-017-9516-7

Zhang, Y., Wang, L., \& Duan, Y. (2016). Agricultural information dissemination using ICTs: A review and analysis of information dissemination models in China. Information Processing in Agriculture, 3(1), 17-29. https://doi.org/10.1016/J.INPA.2015.11.002

Zilberman, D., Goetz, R., \& Garrido, A. (2018). Climate Smart Agriculture Building Resilience to Climate Change (Springer). Roma, Italia. https://doi.org/10.1007/978-3-319-61194-5 
